(c) Elsevier/INRA

Original article

\title{
Sequential GTG-RBA banding pattern in prometaphase chromosomes of cattle (Bos taurus L)
}

\author{
D Di Berardino ${ }^{1 *}, \mathrm{MB} \mathrm{Lioi}^{2}, \mathrm{D}_{\text {Matassino }}{ }^{1}$ \\ 1 Università degli Studi di Napoli, Dipartimento di Scienza \\ della Produzione Animale, 80055, Portici, Naples; \\ 2 Università degli Studi della Basilicata, Istituto di Produzione \\ Animale, Facoltà di Agraria, 85100 Potenza, Italy
}

(Received 14 November 1990; accepted 17 April 1991)

\begin{abstract}
Summary - A sequential GTG-RBA banding procedure, performed for the first time on the same prometaphase chromosomes of cattle, is presented with the aim of establishing correlations between $\mathrm{G}$ and $\mathrm{R}$ bands. The results of the present investigation contributed to the establishment of new standard GTG and RBA-banded karyotypes at prometaphase level, useful for the precise identification of chromosomal abnormalities, comparative cytogenetics and gene mapping in the species Bos taurus L.

sequential banding / GTG-bands / RBA-bands / standardization / cattle

Résumé - Une nouvelle technique de mise en évidence séquentielle des bandes $G$ et $\mathbf{R}$ sur les chromosomes prométaphasiques du bovin (Bos taurus $\mathbf{L}$ ). Une nouvelle technique de mise en évidence séquentielle de bandes $G$ et $R$ est présentée pour la première fois sur les chromosomes prométaphasiques du bovin dans le but d'établir des corrélations entre les bandes $G$ et $R$. Les résultats de cette étude ont contribué à l'établissement de nouveaux caryotypes standards en bandes $G$ et $R$ au niveau prométaphasique. Cette étude est utile pour l'identification précise des anomalies chromosomiques, pour les études de cytogénétique comparée et pour la localisation des gènes de Bos taurus.
\end{abstract}

bandes séquentielles / bandes G / bandes R / standardisation / bovin

\footnotetext{
* Correspondence and reprints
} 


\section{INTRODUCTION}

The Reading conference on the standardization of banded karyotypes of domestic animals (Ford et al, 1980), undoubtedly one of the most important steps in the history of animal cytogenetics, provided for the first time the 'standard' G-banded karyotype of cattle (Bos taurus L) as well as that of other domestic species. Despite its excellent quality, the bovine standard G-banded karyotype soon revealed some limitations for chromosome identification, due mainly to the degree of contraction of the chromosomes used for the standard and, secondarily, to an intrinsic feature of bovine chromosomes, common to all the Bovidae, ie G-negative centromeres and telomeres.

These problems have made it necessary to improve the Reading standard by using less contracted chromosomes and to adopt alternative banding techniques such as RBA and QFQ for standardization of new karyotypes which could be used more widely by the scientific community.

This paper reports the results of the sequential GTG-RBA banding technique performed for the first time on the same prometaphase chromosomes of cattle in order to establish correlation between the GTG and the RBA bands. These results provided an important part of the material used for the discussions at the 2nd International Conference for the Standardization of Banded Karyotypes in Domestic Animals, held at Jouy-en-Josas (France) the 22-26th of May, 1989 (ISCNDA, 1989).

\section{MATERIAL AND METHODS}

Peripheral blood, drawn from the jugular vein of 5 young bulls of the Italian Friesian breed, was cultured at $37.5^{\circ} \mathrm{C}$ for $72 \mathrm{~h}$ in RPMI 1640 medium (Flow, Dutch modification) supplemented with $10 \%$ fetal calf serum (Gibco), $0.1 \%$ Lglutamine and $0.1 \mathrm{ml}$ of pokeweed mitogen (Gibco). $6.5 \mathrm{~h}$ before harvesting cells, $5^{\prime}$-bromodeoxy-uridine (BUdR, Sigma) at a final concentration of $20 \mu \mathrm{g} / \mathrm{ml}$ and $5.5 \mathrm{~h}$ later colcemid solution (Gibco, final concentration of $0.03 \mu \mathrm{g} / \mathrm{ml}$ ) were added. In order to facilitate the spreading of the prometaphase chromosomes the cell suspension was subjected to a stronger hypotonic shock than usual $(0.05 \mathrm{M} \mathrm{KCl})$ at $37.5^{\circ} \mathrm{C}$ for $20 \mathrm{~min}$ and fixed with methanol-acetic acid solution $(3: 1)$ for $1 \mathrm{~h}$, centrifuged, fixed again and left overnight in the refrigerator. Air-dried slides were prepared.

\section{Sequential GTG-RBA banding procedure}

The air-dried slides, 3-5-d old, were treated for GTG banding according to Lin et al (1977); soon after the Giemsa staining, the slides were flooded with phosphate buffer $(\mathrm{pH}=7)$, covered with a coverslip and examined with a Leitz Dialux under bright field optics. The best G-banded prometaphase spreads were selected and photographed with a Kodak microfilm 1454. After microphotography, the coverslip was removed, the slide was destained gently in $30 \%$ ethanol for $10 \mathrm{~min}$, washed in distilled water, air-dried and stained with an acridine orange solution $(0.2 \%$ in phosphate buffer) for $15 \mathrm{~min}$, washed again in tap water, mounted in the same buffer and sealed with paraffin (Di Berardino et al, 1979). The prometaphase 
spreads previously examined for GTG banding were relocated and photographed again for RBA banding with the same Kodak microfilm 1454. Kodabrome F2M and F3M papers were used for printing GTG and RBA banded prometaphase spreads, respectively.

\section{RESULTS}

Figure 1 (A and B) shows, respectively, a GTG-banded prometaphase spread of cattle $(2 n=60, X Y)$ and the same spread sequentially stained for RBA-banding. In order to verify the correspondence between the Reading standard and the prometaphase G-banding pattern, individual chromosomes from figure 1A were arranged, side by side, with the G-banded chromosomes of the Reading standard, as shown in figure 2. From this figure it is possible to verify the great advantage and usefulness of using prometaphase instead of metaphase chromosomes, especially for the identification of the smallest autosomes ranking from pairs No 21-29. All the G-banded prometaphase chromosomes fit very well to the Reading standard, thus providing more information for a definite characterization and identification of individual chromosomes of the species. However, because of chromosome contraction of the G-banded cattle chromosomes reported by the Reading standard, it is quite difficult to distinguish among the chromosomes Nos 25, 27 and 29; hence, it is not fully evident that the actual prometaphase pairs correspond to the ones of the Reading standard.

In order to examine in detail the correlation between the GTG and the RBA banding pattern of individual prometaphase chromosomes of cattle, figure 3 (A, $\mathrm{B}$ and $\mathrm{C}$ ) was prepared in which the GTG-banded prometaphase chromosomes from figure $1 \mathrm{~A}$ ( $b$ and $d$ ) are compared with the sequentially stained RBA-banded chromosomes ( $a$ and $e$ ) and with the 'direct' RBA banded chromosomes $(c)$. From this figure it is possible to verify the correct correspondence between $G$ and $R$ bands in almost all of the chromosomes, including the $X$ and $Y$ sex chromosomes.

\section{DISCUSSION}

The sequential GTG-RBA banding procedure, performed for the first time on chromosome of cattle, is suitable for a specific characterization of individual chromosomes of this species. Previous contributions on the RBA banding pattern in cattle chromosomes (Popescu, 1975; Gustavsson and Hagelthorn, 1976; De Giovanni et al, 1979; 1988; Di Berardino et al, 1979, 1983, 1985a, 1985b; Di Berardino and Iannuzzi, 1982) reported karyotypes which were based, as far as possible, on the Reading G-banded standard karyotype, but a direct correlation between $\mathrm{G}$ and $\mathrm{R}$ bands has not so far been reported. Recently, a G-and R-banding comparison of cattle prometaphase chromosomes arranged according to the Reading system has been reported (Iannuzzi, 1990) but without use of a sequential G-R banding procedure.

The present investigation was carried out in order to make correlations between $G$ and $R$ bands on the same chromosome preparation, thus providing the necessary information for the definition of new standard GTG and RBA banded karyotypes for the species Bos taurus L. 

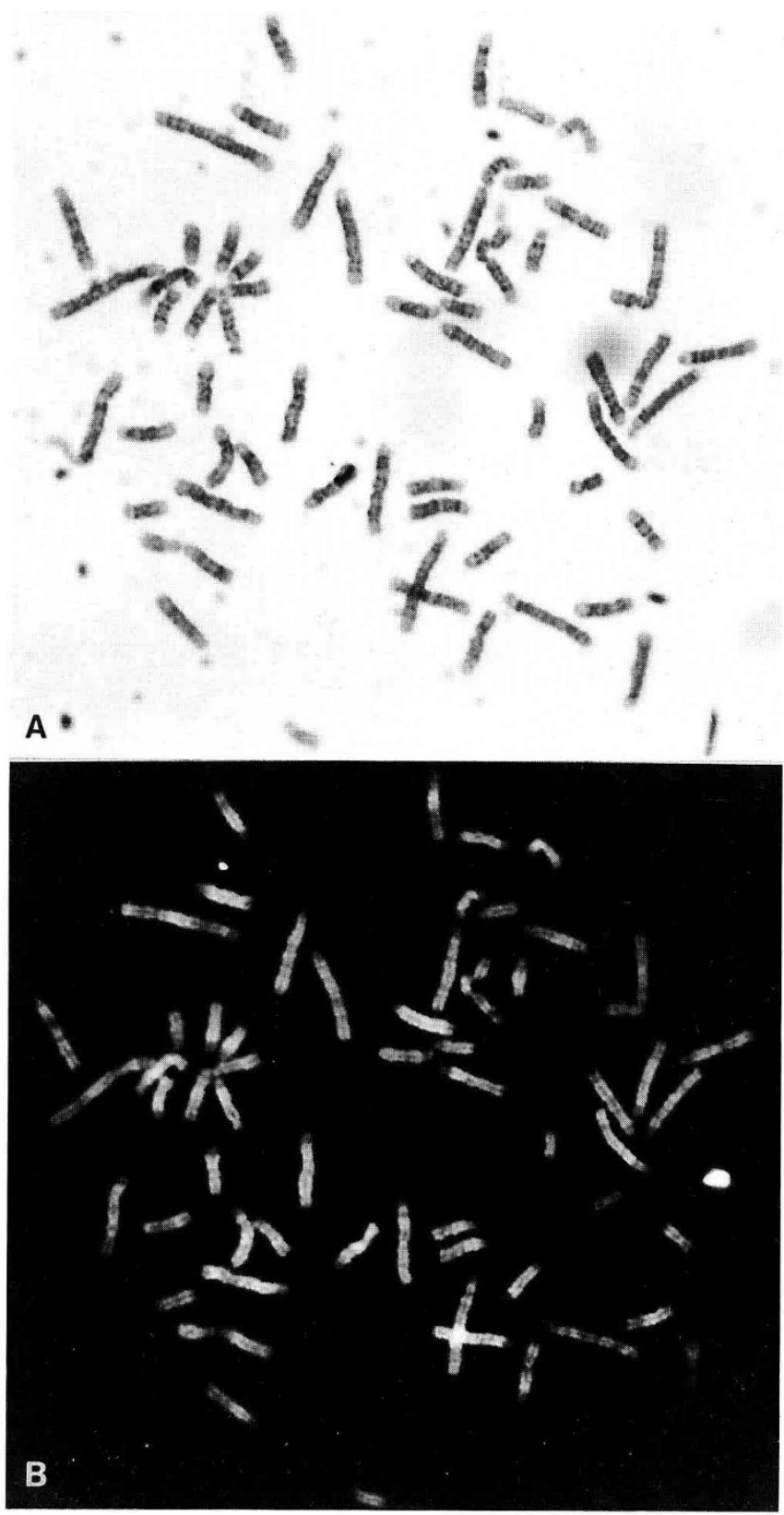

Fig 1. (A) GTG-banded prometaphase spread of cattle $(2 n=60, X Y)$; (B) the same spread sequentially stained for RBA-banding. 

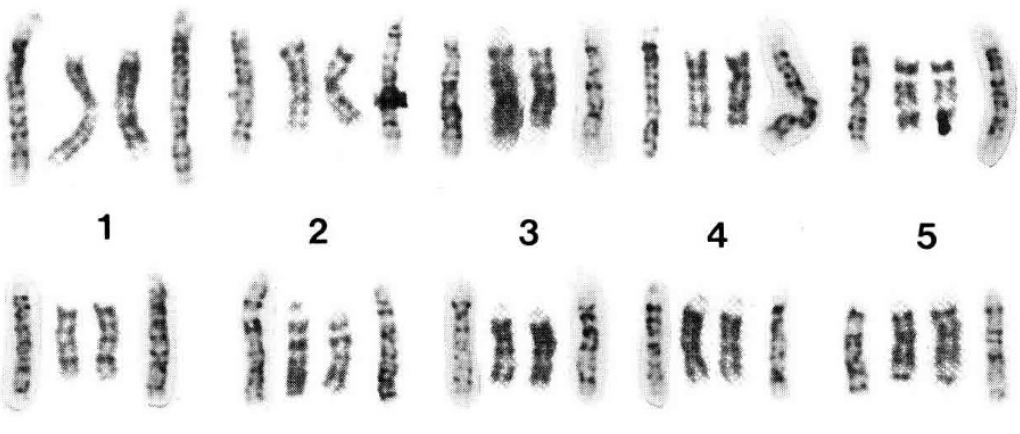

6

7

8

9

10

\section{III}

11

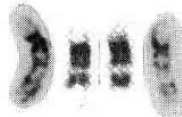

16

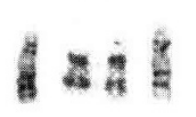

21

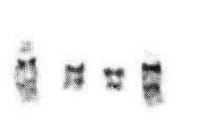

26

\section{(n⿴囗十)}

12 inn?

13
15

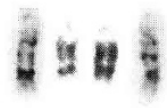

20

15
22

สี $x=5$

27

18

19

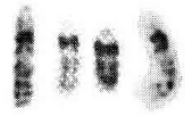

14

2.

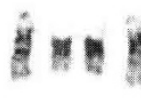

है $n *$ ह

23

24

25

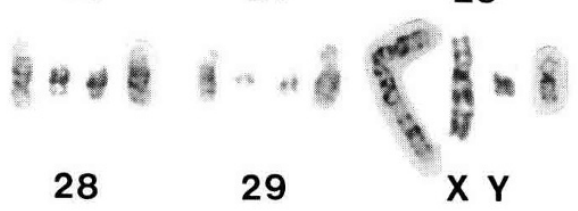

Fig 2. Correspondence between the GTG-banded chromosomes of the Reading standard (at the center of each pair) and the GTG-banded prometaphase chromosomes of figure $1 \mathrm{~A}$ (right and left).

In the sequential procedure reported here, the BUdR incorporation necessary to achieve the RBA banding did not seem to affect the G-banding pattern. Also the trypsin treatment used for GTG-banding did not produce significant effects on the quality of the RBA-banding pattern in almost all of the chromosomes. Therefore, this procedure could also be used for the standardization of GTG and RBA-banded 

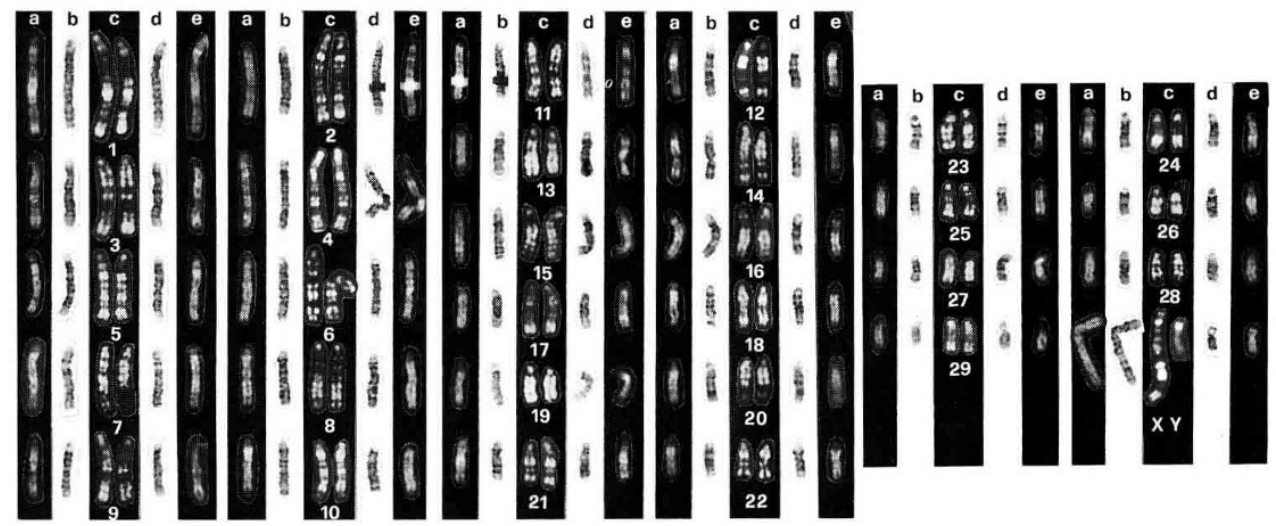

Fig 3. (A, B, C), Comparison of the GTG-banded prometaphase chromosomes of figure $1 \mathrm{~A}(b$ and $d)$ with the sequentially stained RBA-banded chromosomes of figure 1B ( $a$ and $e$ ) and the direct RBA-banded chromosomes $(c)$.

karyotypes of other domestic species for which extensive cytogenetic material is already available.

Other ways using G- and R-banded marker chromosomes, such as centric fusions, translocations and nucleolus organizer chromosomes of Bovidae, as well as the biarmed chromosomes of related species, could provide additional information for a definitive characterization of the banding pattern of individual chromosomes of the species Bos taurus L.

The results of the present paper contributed to the definition of the 'standard' GTG and RBA-banded karyotypes and idiograms of cattle at the prometaphase level (ISCNDA, 1989) useful for precise description and identification of numerical as well as structural chromosomal aberrations, comparative cytogenetics and gene mapping.

Financial support for this study was obtained from the National Research Council (CNR) of Rome, Italy.

\section{REFERENCES}

De Giovanni A, Succi G, Molteni L, Castiglioni M (1979) A new autosomal translocation in Alpine grey cattle. Ann Genet Sel Anim 11, 115-120

De Giovanni A, Molteni L, Succi G, Galiani C, Boscher J, Popescu P (1988) A new type of Robertsonian translocation in cattle. In : 8th Eur Coll Cytog Dom Anim, Bristol 19-22 July 1988, 53-59

Di Berardino D, Iannuzzi L, Ferrara L, Matassino D (1979) A new case of Robertsonian translocation in cattle. $J$ Hered 70,436

Di Berardino D, Iannuzzi L (1982) Detailed description of R-banded bovine chromosomes. $J$ Hered $73,434-438$ 
Di Berardino D, Iannuzzi L, Di Meo GP (1983) Localization of BrdU induced break sites in bovine chromosomes. Caryologia 36, 285-292

Di Berardino D, Lioi MB, Iannuzzi L (1985a) Identification of nucleolus organizer chromosomes in cattle (Bos taurus L) by sequential silver staining + RBA-banding. Caryologia 38, 95-102

Di Berardino D, Iannuzzi L, Lioi MB (1985b). The high resolution RBA banding pattern in bovine chromosomes. Cytogenet Cell Genet 39, 136-139.

Ford CE, Pollock DL, Gustavsson I (1980) Proceedings of the First International Conference for the Standardization of Banded Karyotypes of Domestic Animals, Reading, 1976.

Gustavsson I, Hagelthorn M (1976) Staining technique for definite identification of individual cattle chromosome in routine analysis. $J$ Hered $67,175-178$

Iannuzzi L (1990) An improved characterization of cattle chromosomes by means of high resolution G- and R-band comparison. J Hered 81, 80-83

ISCNDA (1989) International System for Cytogenetic Nomenclature of Domestic Animals (Di Berardino D, Hayes H, Fries R, Long S, eds), Cytogenet Cell Genet 53, 65-79

Lin CC, Newton DR, Church RB (1977) Identification and nomenclature for Gbanded bovine chromosomes. Can J Genet Cytol 19, 271-282

Popescu CP (1975) Essai d'identification des chromosomes bovins (Bos taurus L) à l'aide du marquage au 5-bromo-deoxy-uridine (BrdU). $2^{e}$ Coll Eur de Cytogénétique des Animaux Domestiques. Giessen, 59-64 